\title{
Phrenic neuropathy in chronic renal failure
}

\author{
Udo Zifko, Martin Auinger, Gerhard Albrecht, Thomas Kästenbauer, \\ Heinz Lahrmann, Wolfgang Grisold, Theodor Wanke
}

\begin{abstract}
Background - Peripheral neuropathy and alterations in diaphragmatic muscle function are frequently caused by uraemia. Phrenic nerve function in patients with end stage renal failure, however, has not been examined to date.

Methods - An electrophysiological study of the phrenic nerve was performed to determine its possible involvement in 32 nondiabetic patients with end stage renal disease undergoing chronic haemodialysis.

Results - Seventeen patients had electrophysiological signs of peripheral neuropathy in at least one of the investigated nerves and 14 of the 17 showed pathological phrenic nerve latencies. Delayed phrenic nerve latencies correlated clearly with pathological peroneal nerve conduction velocities.
\end{abstract}

Conclusions - Phrenic neuropathy is a frequent complication of uraemia.

(Thorax 1995;50:793-794)

Neurological

Department, Kaiser

Franz Josef Spital

and L. Boltzmann

Institute of

Neurobiology,

Krankenhaus

Baumgartner Höhe

U Zifko

G Albrecht

W Grisold

Third Medical

Department and L.

Boltzmann Institute of Metabolism,

Krankenhaus Lainz

$M$ Auinger

T Kästenbauer

Pulmonary

Department and L. Boltzmann Institute for Environmental

Research,

Krankenhaus Lainz

H Lahrmann

T Wanke

Vienna, Austria

Reprint requests to: Dr T Wanke, Pulmonary Department, Krankenhaus Lainz, Wolkersbergenstraße 1, A-1130 Vienna, Austria. 1, A-1130 Vienna, Austria.

Received 3 January 199 Returned to authors 21 February 1995 22 March 1995 Accepted for publication 19 April 1995
Keywords: phrenic neuropathy, uraemia, haemodialysis.

One of the major complications of uraemia renal dialysis. ${ }^{1}$ Diaphragmatic muscle dysfunction has also been reported to be a complication of uraemia. ${ }^{2}$ Impaired diaphragmatic muscle function has been considered to be due to myopathy. ${ }^{2}$ Although phrenic neuropathy is known to cause diaphragmatic weakness, ${ }^{34}$ the presence of phrenic neuropathy in patients with chronic renal failure has not been investigated. The aim of this study was to detect involvement of the phrenic nerve in patients with non-diabetic uraemia treated by haemodialysis, and to determine the potential correlation of phrenic neuropathy with peripheral neuropathy.

\section{Methods}

Thirty two patients (19 men) undergoing renal dialysis were investigated. Their ages ranged from 14 to 69 years with a mean (SD) of 49 (13). All were on a haemodialysis programme three times a week for a mean duration of 16 (19) months (range 3-84). The causes of renal failure were chronic glomerulonephritis $(n=$ $15)$, vascular $(n=10)$, pyelonephritis $(n=4)$, and unknown $(n=3)$. Patients with diabetes is peripheral neuropathy which is found in approximately half of all patients undergoing mellitus, amyloidosis, radiological cardiorespiratory abnormalities, hepatic failure, or on known neurotoxic medication were excluded. All patients were studied by electrophysiology on a day between two dialysis sessions.

Phrenic nerves were examined by the method described previously. ${ }^{5}$ Control values for phrenic nerve conduction studies were obtained in our laboratory and did not differ significantly from previously reported studies ${ }^{67}$ (right mean latency: $7.47(0.79) \mathrm{ms}$, left mean latency: $7.50(0.87) \mathrm{ms})$. Abnormal phrenic nerve latencies were defined as more than 2 SD beyond the mean - that is, $>9.1 \mathrm{~ms}$ for the right and $>9.3 \mathrm{~ms}$ for the left phrenic nerve. Although the compound action potentials of all phrenic nerves were investigated, this parameter was not used for further analysis due to frequent subcutaneous oedema in patients on haemodialysis.

Median nerve (motor and sensory antidromic), peroneal nerve, and sural nerve (orthodromic) velocities were measured and the results compared with the reference values listed by Ludin. ${ }^{8}$ All phrenic and peripheral nerve conduction data were recorded, analysed, and printed using a Medelec Mystro MS 20.

Statistical analysis was performed by the Student's $t$ test and regression analysis.

\section{Results}

Phrenic nerve responses were abnormally prolonged in 14 patients, bilaterally in 13 and unilaterally in one. In all patients there was no significant difference between right and left phrenic nerve latencies, with the right averaging $8.92(1.21) \mathrm{ms}$, and the left $9 \cdot 11(1.58) \mathrm{ms}$. The mean latency in the group with delayed latency was $10.02(0.68) \mathrm{ms}$ (right phrenic nerve) and 10.72 (0.87) ms (left phrenic nerve).

The motor median nerve velocity was abnormal in five patients with a mean of $49.6 \mathrm{~m} / \mathrm{s}$. In seven cases the sensory median nerve velocity in the forearm was beyond the normal range (mean velocity $49 \cdot 3 \mathrm{~m} / \mathrm{s}$ ). Peroneal nerve responses were obtainable in 31 patients and were abnormal in 13 (mean velocity $41.4 \mathrm{~m} / \mathrm{s}$ ). Sural nerve velocities were not obtainable in five patients and were delayed in 12 (mean velocity $40 \cdot 2 \mathrm{~m} / \mathrm{s}$ ).

In order to determine whether the slowing of peripheral conduction corresponded to prolongation of the phrenic nerve latency we correlated the right phrenic motor response with 
Correlation of right phrenic nerve latency and peroneal nerve motor conduction velocity (MCV) in patients on haemodialysis $(n=31)$; $r=-0.56, p<0.001$.

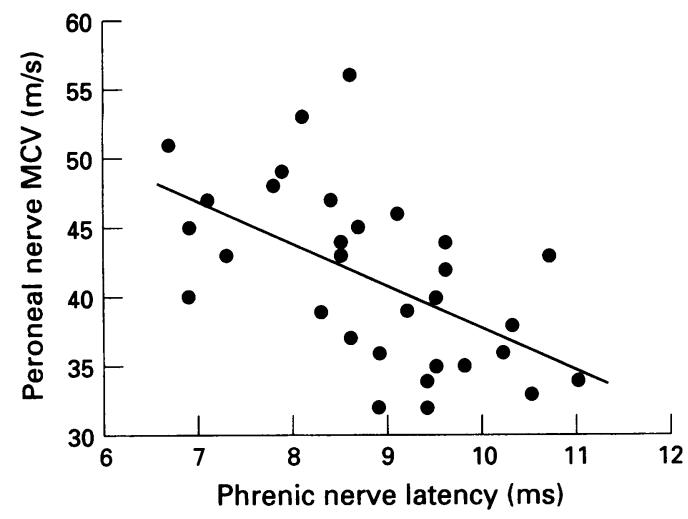

peroneal motor conduction. A significant relation existed between these two variables $(r=$ $-0.56, \mathrm{p}<0.001)$ as shown in the figure.

\section{Discussion}

To the best of our knowledge this is the first study to demonstrate the occurrence of phrenic neuropathy in patients on chronic haemodialysis. Phrenic nerve involvement has been described in several neuropathies including critical illness polyneuropathy, the GuillainBarré syndrome, brachial neuritis, hereditary motor and sensory neuropathy type 1, porphyria, leprosy, and Waldenström's macroglobulinaemia. ${ }^{910}$
All our patients with delayed phrenic nerve latency showed electrophysiological signs of peripheral neuropathy. In addition, delayed phrenic nerve latencies correlated significantly with pathological peroneal nerve conduction velocity.

Since inspiratory muscle dysfunction is a frequent clinical feature in uraemic patients ${ }^{2}$ and phrenic nerve neuropathy is known to contribute to diaphragmatic weakness, ${ }^{3}$ the detection of phrenic nerve involvement is of particular interest.

1 Schaumburg HH. Other systemically related disorders. In Schaumburg HH, Berger AR, Thomas PK eds. Disorder of peripheral nerves. Philadelphia, FA Davis Company, 1992:151-73.

2 Prezant DJ. Effect of uraemia and its treatment on pulmonary function. Lung 1990;168:1-14.

3 Wilcox PG, Pardy RL. Diaphragmatic weakness and paralysis. Lung 1989;167:323-41.

4 Laroche CM, Moxham J, Green M. Respiratory muscle weakness and fatigue. $O f$ Med 1989;265:373-97.

5 Mier A, Brophy C, Moxham J, Green M. Twitch pressures in the assessment of diaphragm weakness. Thorax 1989; 44:990-6.

6 Gourie-Devi M, Ganapathy GR. Phrenic nerve conduction time in Guillain-Barré syndrome. $\mathcal{F}$ Neurol Neurosurg Psychiatry 1985;48:245-9.

7 Mier A, Brophy C, Moxham J, Green M. Phrenic nerve stimulation in normal subjects and in patients with diaphragmatic weakness. Thorax 1987;42:885-8.

8 Ludin HP. Reference values. In Ludin HP, ed. Practical electromyography. Stuttgart: Enke, 1981:139-71.

cectromyography. Stuttgart. Enke, 1 , Lieberman JS, Fowler WM. Evaluation of phrenic nerve and pulmonary function in hereditary motor and sensory neuropathy type 1. Muscle Nerve 1992;15:459-62.

10 Bolton CF. Clinical neurophysiology of the respiratory system. Muscle Nerve 1993;16:809-18.
Bradbury Adult Cystic Fibrosis Unit, Wythenshawe Hospital, Southmoor Road, Manchester M23 9LT, UK J Abbott M Dodd

A K Webb

Reprints request to: Dr A K Webb.

Received 5 December 1994 Returned to authors 20 January 1995 Revised version received 15 March 1995 Accepted for publication 28 March 1995

\begin{abstract}
Background - An investigation was carried out to determine whether patients with cystic fibrosis, their close companions, and physician perceived the severity of the disease and the level of patient self care similarly.

Methods - Sixty adults with cystic fibrosis (16-44 years), their close companion, and physician independently completed scales measuring their perceptions of disease severity and patient self care on three occasions over a two year period. Percentage predicted forced expiratory volume in one second $\left(F E V_{1}\right)$ and forced vital capacity (FVC), Shwachman score, and weight for height were recorded following each assessment.
\end{abstract}

Results - Patients and close companions considered the disease to be less severe than their physician. Fifty patients $(83 \%)$ rated their health as "above/well above average", and 49 (82\%) close companions rated the patient's health in the same way, but only $21(35 \%)$ patients were considered by their physician to have mild disease. Differences also emerged in the estimation of patient self care; 48 close companions $(80 \%)$ rated patients as "very good" or "excellent" in their self care, compared with $26(44 \%)$ of the patients themselves. Only nine patients $(15 \%)$ were considered to achieve this level of self care by their physician. Over the two year period the physician's ratings of severity increased in accordance with the decline in lung func- 